\title{
Um projeto de intervenção socioeducativa em prol do envelhecimento ativo
}

\section{A socio-educational intervention project for active aging}

\author{
Nunes S. C. R., Antunes, M. C. \\ Universidade do Minho, Portugal
}

\begin{abstract}
Resumo
A intervenção aqui descrita resultou de um trabalho de investigação/intervenção desenvolvido com população adulta e idosa a frequentar uma oficina de educação de adultos, cuja finalidade se centrou na promoção do envelhecimento ativo. Recorrendo ao paradigma interpretativo-hermenêutico, foi desenvolvido um trabalho de investigação-ação participativa utilizando as técnicas de animação sociocultural. A intervenção teve resultados positivos dado que na avaliação final os participantes destacaram os benefícios do projeto. Este projeto reiterou a importância da animação sociocultural como intervenção promotora de aprendizagens, do bem-estar e da qualidade de vida junto da população adulta e idosa.
\end{abstract}

Palavras chave: educação de adultos, intervenção comunitária, envelhecimento ativo.

\begin{abstract}
The intervention here described resulted from a research / intervention work developed with adult and elderly people who attended an adult education workshop, which purpose was to promote active aging. The authors developed a participatory action-research, applying the interpretivehermeneutic paradigm and resorting to sociocultural animation techniques. The intervention had positive results as the final evaluation revealed, the participants highlighted the benefits of the project. This project reiterated the importance of social and cultural activities regarding the adult and elderly's learning processes, welfare and quality of life.

Keywords: adult education; community intervention; active aging.
\end{abstract}

O "universal" e progressivo envelhecimento da população deve-se ao crescimento da longevidade e ao decréscimo da natalidade (Barros de Oliveira, 2005; OMS, 2008; Paúl, 1997), originando assim, o aumento da população idosa em detrimento da população jovem (Carrilho \& Craveiro, 2015).

Com o processo de envelhecimento cresce o número de limitações, patologias, perdas e dificuldades, de natureza biológica, socioeconómica, ambiental, física, psicológica e afetiva (OMS, 2008; Barros de Oliveira, 2005; Eizirik, Kapczinski \& Bassols, 2007). Uma vez que, "as capacidades de adaptação do ser humano vão diminuindo, tornando-o cada vez mais sensível ao meio ambiente que, consoante as restrições implícitas ao funcionamento do idoso, pode ser um elemento facilitador ou um obstáculo para a sua vida" (Jacob, 2007:3).

Tendo em conta esta conceção, são atribuídas várias caraterísticas à população mais idosa, gerando estereótipos e preconceitos discriminatórios e opressivos assentes em preceitos de que os idosos são indivíduos inúteis e incapazes de aprender e de realizar os seus desejos e vontades, levando-os, por vezes, a considerarem os seus conhecimentos/saberes e vivências irrelevantes (Oliveira, Oliveira e Scortegagna, 2010). No entanto, torna-se iminente incrementar e reconhecer as mais valias adquiridas com o aumento da idade, tais como, "a sabedoria, a maturidade emocional, a capacidade de usar estratégias pró-ativas capazes de dar maior significado à vida" Barros de Oliveira (2005:7).

Partindo destas perspetivas, compreende-se a necessidade de integrar a população idosa na sociedade valorizando as suas experiências de vida e as suas capacidades, assumindo a educação um meio de empowerment dos indivíduos possibilitando um envelhecimento ativo. Neste enquadramento é imputada à educação, nomeadamente à educação de adultos, uma função social crucial, uma vez que, procura aprimorar os saberes/conhecimentos e experiências dos sujeitos, facilitando um crescimento continuado, assim como, os vínculos e participação ativa na sociedade (Cachioni \& Neri, 2004), sendo, assim, percecionada como meio de desenvolvimento global, multidimensional e harmónico dos indivíduos (DIAS, 2009).

Segundo Antunes (2015) o envelhecimento é, de certa forma, influenciado pela maneira de vida. Apreende-se assim, o interesse no desenvolvimento de políticas e projetos promotores de um envelhecimento bemsucedido e saudável - um envelhecimento ativo. Partindo deste contexto, as dinâmicas educativas, devem assentar no sentido holístico do envelhecimento educando os sujeitos numa perspetiva proactiva e emancipadora, dotando-os de saberes/conhecimentos, comportamentos/atitudes e capacidades fundamentais para um envelhecimento bem-sucedido (Antunes, 2015), o que obriga a um trabalho multidimensional e coletivo, considerando a educação impulsionadora de mudanças da realidade individual e coletiva.

Torna-se, então, imprescindível adotar políticas e práticas promotoras de um envelhecimento ativo, tendo em conta o crescimento e/ou manutenção das competências dos sujeitos (OMS, 2015), considerando a 
autonomia, a aprendizagem e permanecer ativo (DGS, 2012). O envelhecimento ativo refere-se ao "processo de otimização de oportunidades para saúde, participação e segurança, para melhorar a qualidade de vida das pessoas à medida que envelhecem" (OMS, 2008: 10). Respeitante a sujeitos ou grupos, proporciona que se habilitem no encontro do seu bem-estar biopsicossocial, com uma participação ativa ao nível económico, sociocultural, espiritual e cívico (Jacob, 2007).

Destarte, é fundamental implicar os indivíduos ativamente na sua educação, colaborando nas atividades que potencializem um envelhecimento ativo, tendo em conta comportamentos impulsionadores de saúde e bemestar pessoal e social, permitindo uma maior coesão e produtividade, oferecendo aos sujeitos uma maior satisfação e qualidade de vida (ONU, 2003).

O envelhecimento ativo é, assim, fomentado pela participação dos adultos em atividades de caracter sociocultural, económico, desportivo, recreativo e/ou de voluntariado. Neste contexto, o envelhecimento ativo torna-se um desafio e uma oportunidade apostando, quer na promoção da solidariedade entre gerações, quer assegurando uma sociedade inclusiva (Carilho \& Craveiro, 2015).

O projeto que aqui descrevemos foi desenvolvido no âmbito do Mestrado em Educação - Área de Especialização em Educação de Adultos e Intervenção Comunitária da Universidade do Minho em parceria com uma Junta de Freguesia, e teve como finalidade a criação de um programa educativo favorecedor de um envelhecimento bem-sucedido, onde foram dinamizados diversos tipos de atividades a nível físico, cognitivo, lúdico, social e afetivo, que permitiram desenvolver as capacidades funcionais do adulto $\mathrm{e}$ adulto idoso (mobilidade, memória, criatividade, reflexão crítica); fomentar o convívio e as relações interpessoais.

No que concerne à natureza metodológica, este projeto orientou-se segundo o paradigma de investigação qualitativa interpretativa, dado que o que pretendíamos era aprofundar os fenómenos no seu espaço natural analisando a sua complexidade, com o intuito de melhor compreender os comportamentos da população estudada. Neste sentido, a recolha de informação foi realizada por meio de uma relação direta com os sujeitos no seu contexto, por forma, a conhecer como analisam o seu mundo, (Bogdan \& Biklen, 1994; Hernandez Sampieri, Baptista Lucio \& Fernandez-Collado, 2003). No âmbito deste paradigma de investigação o propósito do agente investigador é o de compreender e interpretar a leitura que os indivíduos apresentam do seu mundo (Giroux \& Tremblay, 2011), considerados seres em permanente interação com o contexto, em que o conhecimento é construído com base na subjetividade e vivências dos sujeitos, num processo dinâmico entre os fenómenos e sua interpretação, assumindo a intervenção, um elemento promotor de interações sociais (Caride, 2004; Hernandez Sampieri, Baptista Lucio \& Fernandez-Collado, 2003).

A metodologia educativa utilizada foi a investigaçãoação-participativa apoiada nas técnicas de animação sociocultural, o que favoreceu a motivação, a dinamização e a participação dos envolvidos no seu processo educativo. $\mathrm{O}$ recurso a esta metodologia permitiu, ainda, a concomitância do modo de conhecer e intervir, implicando a participação dos intervenientes no programa de estudo e ação (Ander-Egg, 2003; Castillo Arredondo e Cabrerizo Diago, 2003).

\section{Método}

\section{Participantes}

Neste projeto participaram oitenta e dois adultos/idosos com idades compreendidas entre os 56 e os 82 anos.

Da análise ao inquérito por questionário aplicado aos 29 indivíduos com os quais iniciamos o projeto pudemos aferir que 24 elementos eram do sexo feminino e 5 do sexo masculino. Quanto ao estado civil, verificamos que 23 elementos eram casados, 4 viúvos, 1 solteiro e 1 divorciado. No que às habilitações literárias diz respeito, 21 participantes completaram o primeiro ciclo, 4 pessoas o terceiro ciclo e 3 o segundo ciclo, 1 não sabia ler nem escrever. Importa ainda referir que 25 participantes eram reformados, 4 encontravam-se desempregados, 15 trabalharam no sector têxtil, 3 na restauração e hotelaria, 2 desempenharam funções de auxiliares educativos, 2 motoristas e um técnico mecânico.

\section{Procedimentos}

Nesta investigação/intervenção recorremos a diversas técnicas de recolha de informação: inquérito por questionário, entrevista, pesquisa e análise documental, observação participante, diário de bordo, conversas informais e registo de imagem. No que às técnicas de intervenção diz respeito, selecionamos a animação sociocultural, com o desígnio de promover a transformação da qualidade de vida através da participação dos implicados em dinâmicas socioculturais (Ander-Egg, 2000). Optamos pela utilização, das técnicas de grupo, de informação/comunicação e das técnicas e procedimentos orientados para implementação de atividades artísticas e lúdicas.

Numa fase prévia à recolha de dados (inquéritos por questionário e entrevista), fornecemos aos participantes informações sobre o enquadramento institucional e objetivos do estudo e clarificamos as questões éticas, nomeadamente, o caráter voluntário da participação no estudo, a garantia do anonimato e confidencialidade dos dados recolhidos e o consentimento para a divulgação (anónima) dos resultados.

Quanto ao tratamento de dados, os quantitativos foram analisados usando uma estatística descritiva simples, por sua vez, o tratamento dos dados qualitativos obedeceu às indicações de análise interpretativa.

Este projeto de investigação/intervenção integrou três fases. A $1^{\mathrm{a}}$ fase, a de Sensibilização e diagnóstico de necessidades, em que as atividades visaram essencialmente a inserção no contexto de intervenção e a divulgação do projeto. Nesta fase, as atividades incidiram essencialmente em reuniões com responsáveis de várias instituições da comunidade, para divulgação do projeto, criação de parcerias, divulgação do projeto (porta a porta, cartazes e criação de uma rede social) e respetivo convite para participar, assim como procedemos à aplicação e análise de inquéritos por questionário para realização da 
avaliação de diagnóstico. Complementamos a nossa aproximação e aprofundamento à realidade estudada através da observação direta e conversas informais com potenciais participantes e informantes chave, não descorando a pesquisa documental.

A $2^{\mathrm{a}}$ Fase correspondeu à Implementação das Atividades. Partindo dos interesses, necessidades e potencialidades dos participantes foram desenvolvidas 6 Oficinas. 1) Oficina de estimulação motora e cognitiva, com várias atividades desportivas e mentais, permitindo, entre outros, o desenvolvimento e/ou manutenção do bem-estar físico e mental. 2) Oficina de TIC, que visou essencialmente combater a infoexclusão, incrementar o uso das novas tecnologias e fomentar a autonomia pessoal e social, através da exploração das ferramentas das novas tecnologias. 3) Oficina de expressões artísticas, que subdividida em vários grupos (grupo de cantares, grupo de cavaquinhos, grupo das manualidades, grupo agulhas e companhia, grupo voluntários de animação e grupo de teatro), procurou desenvolver competências artísticas, favorecer o desenvolvimento cognitivo, emocional e cultural, estimular a criatividade, expressividade e espírito crítico, assim como despertar para o sentido estético, equilibrado e harmónico. 4) Oficina de educação/promoção para a saúde, assente em palestras, ações de sensibilização e experimentação pretendeu basicamente, incrementar boas práticas de higiene de vida, adquirir conhecimentos sobre envelhecimento saudável e sensibilizar para a melhoria da qualidade de vida. 5) Oficina cultural, com a celebração de datas festivas, a organização de vários encontros de poesia, teatro, cantares, e exposições, bem como, visitas guiadas e jogos tradicionais e lúdicos, intentou combater o isolamento cultural, incutir hábitos culturais e o desenvolvimento de competências cognitivas e socioculturais. 6) Oficina de (in)formação de natureza sociocultural, informativa e educativa, procurou sensibilizar para os cuidados de segurança e para a aquisição de conhecimentos básicos de primeiros socorros, mediante ações de sensibilização, demonstração e experimentação. Simultaneamente foi realizado o Acompanhamento e Gestão de Casos a três indivíduos, com o principal objetivo de os dotar de ferramentas úteis para o seu dia-a-dia e combater o isolamento social, desenvolvemos atividades de estimulação cognitiva, gestão domestica e higiene de vida, além do acompanhamento social necessário. Foi ainda realizado um Seminário no âmbito da Educação de Adultos e Intervenção Comunitária, por forma a conhecer e disseminar, particularmente as boas práticas de Educação de Adultos e Intervenção Comunitária existentes no concelho, estimular as relações institucionais e demonstrar as competências dos adultos afetos aos projetos apresentados. Com recurso a um inquérito por questionário procedemos, também, à avaliação contínua, com a finalidade, de monitorizar a aceitação e adequação das atividades, para que se necessário estas fossem ajustadas ou alteradas. Esta fase, teve como premissa o desenvolvimento pessoal e social, a transformação e mudança social e cultural, apostando na participação ativa, na interação e no empoderamento dos envolvidos, assim como na sua autoeducação/formação e atitude reflexiva e crítica (Antunes, 2008; Caride, 2004; Castillo Arredondo e Cabrerizo Diago, 2003; García; Sánchez, 1997).

A $3^{\mathrm{a}}$ fase, integrou a Avaliação Final, foi efetuada através de inquérito por questionário aplicado a todos os participantes, uma entrevista estruturada realizada a 10 participantes e uma entrevista semiestruturada realizada ao acompanhante de estágio, além da recolha de testemunhos recolhidos no Seminário e nos diários de bordo.

\section{Resultados}

Analisando os dados recolhidos consideramos que os resultados obtidos foram ao encontro dos objetivos inicialmente definidos.

Através da análise aos inquéritos, verificamos que as oficinas mais frequentadas foram a de estimulação motora e cognitiva, (59 participantes) e oficina cultural (50 participantes). A oficina de expressões artísticas foi frequentada por 45 indivíduos, a de educação/promoção para a saúde por 41, a de (in)formação por 25 e a de TIC por 17. Quanto ao grau de satisfação relativamente à participação nas oficinas, numa escala de Likert: 1 . Bastante satisfeito; 2 Muito satisfeito; 3. Satisfeito; 4. Pouco Satisfeito e 5. Nada Satisfeito, 65 responderam "Bastante Satisfeito", 3 "Muito Satisfeitos" e, 1 "Satisfeito". Estes resultados, corroboram as respostas às entrevistas em que afirmaram "gostei muito" (e. A) ou "fiquei a gostar muito" (e. D). À questão referente às expetativas das oficinas frequentadas, 64 responderam que corresponderam bastante, 4 muito e 1 satisfatório. Nas entrevistas referiram que as oficinas tiveram um impacto muito positivo nas suas vidas, "mudou para melhor, mais alegria e mais vontade de viver" (e. G), ou ainda, "estas oficinas foram uma mais-valia na minha vida [...], estas atividades foram o melhor que me pode acontecer (e. I). Em relação, à estrutura e conteúdos das atividades desenvolvidas, 62 consideraram bastante adequados e 7 muito adequados. Nas entrevistas mencionam "as oficinas foram tão interessantes que nunca me cansava de estar presente" (e. J), declarando que aprenderam "coisas que não sabia fazer" (e. D), "muita coisa que para mim foi importante" (e. F) e "muito útil" (e. J). Questionada a perceção dos participantes pela sua aprendizagem 65 responderam que as atividades contribuíram bastante para o aumento da sua aprendizagem, 3 muito e 1 satisfatório. Nas entrevistas afirmaram "adquiri mais conhecimentos em todos os aspetos de aprendizagem" (e. D), "nas oficinas de TIC melhorei muito" (e. B), nas entrevistas todos consideraram que retiraram boas aprendizagens nas várias oficinas em que participaram, "aprendi muito, como por exemplo, a partilhar as minhas ideias e aquilo que desconhecia que era saber cantar e contar com as outras colegas" (e. H), "foi maravilhoso partilhar ideias, trabalhar em conjunto" (e. I). Interrogados sobre o contributo das oficinas para o envelhecimento ativo, 65 dos inquiridos consideraram bastante importante e 4 muito importante. Nas entrevistas reconheceram que as atividades tiveram benefícios ao nível do envelhecimento ativo, já que "estas atividades tiraram-nos da comodidade 
das nossas casas [...] ficamos mais ativos" (e. E), com "mais alegria para viver e dar mais alegrias às outras pessoas. Senti que somos mais prestáveis com os outros e ganhamos novas amizades" (e. E), além de "estar sempre bem-disposta e pronta ajudar o próximo naquilo que precisa" (e. H). Consideramos ainda, ter objetivos de vida, positivo para o envelhecimento ativo, "aquela canseira e vontade de chegar aquela hora ter de sair de casa e não nos sentarmos no sofá a ver as horas passarem, assim aprendemos algo que nos orgulhamos porque fomos nós que fizemos" (e. I), "estas oficinas começaram numa altura muito má da minha vida [...], a minha participação nas oficinas foram momentos extraordinários [...], que mudaram tudo, foi uma maisvalia" (e. J). Procuramos ainda aferir em que medida as oficinas frequentadas contribuíram para o bem-estar físico, mental e social dos participantes, 66 consideraram que as oficinas tiveram um contributo "bastante importante" e 3 consideraram "muito importante". Nas entrevistas realizadas muitos testemunhos afirmavam que as atividades contribuíram consideravelmente para o aumento da qualidade de vida e bem-estar, "aumentou a minha qualidade de vida e bem-estar, porque estou mais ocupada a fazer o que gosto" (e. A), frisando a sua variável psicológica "acho reconfortante para o bemestar psicológico" (e. F), “em termos psicológicos a mim ajudou-me muito, porque sabia que naqueles dias tinha atividades" (e. D). Destacaram também, na vertente social e cultural a diminuição do isolamento, "não me isolo tanto, convivo com várias pessoas das várias atividades" (e. F), "não houve isolamento... o tempo estava todo preenchido porque todos os dias havia atividades [...]. Isolamento não há, foi embora" (e. I), tendo em conta o "convívio maravilhoso que preenchia as horas de solidão aprendendo sempre [...] que afastaram o isolamento" (e. J), "convivi muito, fiz várias visitas [...] e assisti a peças de teatro muito giras e engraçadas. Participei em algumas festas" (e. A), sendo que estas saídas, propiciam "estar sempre pronta para as atividades" (e. H). As redes sociais têm também um papel importante para a diminuição das condições de isolamento, "para mim deixou de existir isolamento porque passei a comunicar com outras pessoas pessoalmente e também através das redes sociais" (e. B). Por forma a consolidar a ideia que as atividades desenvolvidas contribuíram para o bem-estar físico, mental e social dos participantes, um elemento respondeu que "quando saio para conviver com essas pessoas que conheci fico muito melhor e quando chego a casa já fico a pensar quando é o próximo convívio" (e. C). Quanto à importância das atividades realizadas para a manutenção e/ou desenvolvimento das capacidades cognitivas, físicas e sociais, 66 elementos responderam que as oficinas frequentadas foram "bastante importantes" para a manutenção/desenvolvimento das suas competências e 3 consideraram "muito importante". Um dos entrevistados referiu "temos de certeza mais habilidade de participação e mais conhecimentos culturais" (e. E), um outro reforçou expondo que "a minha vida passou a ser mais dinâmica porque ocupo o tempo livre com o que gosto" (e. C). Á questão do inquérito relativa ao grau de satisfação pelo trabalho realizado pela estagiária, 68 inquiridos concordaram estar bastante satisfeitos e um muito satisfeito, já na entrevista, reconheceram o empenho da mesma, acrescentando que esta, "procurou fazer um pouco de tudo, tudo aquilo que pedíamos, obrigada, excelente profissional" (e. A), expresando "tivemos uma excelente profissional" (e. G), não faltando a gratidão demonstrada, refletida em por exemplo "tenho de agradecer muito" (e. D). Interrogados sobre o interesse em continuar a participar em atividades deste género, 64 responderam estarem "bastante interessados" e 5 "muito". Os entrevistados, são da opinião de que "estas atividades deveriam continuar porque é uma mais-valia para as pessoas que participam nelas" (e. C), assim como, para todas as pessoas que quiseram participar" (e. B). Defenderam ainda a sua replicação, salientando que "deveria haver sempre atividades nas freguesias para pôr o pessoal mais ativo" (e. G). No espaço deixado nos inquéritos por questionário, para que pudessem emitir as suas sugestões/opiniões, 6 elementos expressaram a sua opinião de que projetos desta índole deveriam continuar, 1 reforçou esta opinião escrevendo que foi muito bom. Comprovando os pareceres dados ao longo da implementação das atividades, onde os participantes se mostravam satisfeitos e participativos e envolvendo-se em várias atividades e/ou oficinas, "para mim foi $o$ melhor que me podia surgir porque já estou em casa há anos e foi a forma de ocupar os tempos livres" (e. D).

Por sua vez, a entrevista ao acompanhante de estágio viabilizou a opinião sobre a importância e o impacto deste projeto. Interrogado sobre o impacto das oficinas desenvolvidas, o acompanhante, fazendo referencia, ao feedback do parecer dos participantes e ao que pôde presenciar, salientou que o projeto teve uma satisfação bastante considerável "sendo o reflexo dessa mesma satisfação por parte de todos junto dos participantes" (e. 1). Quanto à questão sobre o envelhecimento ativo, na sua opinião as atividades realizadas contribuíram "sem sombra de dúvida" (e. 1) para um envelhecimento ativo, aludindo a envolvência da população em torno das iniciativas realizadas e a vontade manifestada em continuar a participar nas atividades, o que refletindo, o sinal de um resultado vantajoso para os participantes. Indagado sobre a relevância das atividades desenvolvidas na comunidade, assinalou a especificidade da população uma "caracterização de certa forma particular da população [desta vila]" (e. 1), representada por um grande número de pessoas "considerada velha para trabalhar, mas nova para a reforma" (e. 1), que responsabiliza a autarquia ter uma posição atenta, por forma a evitar, situações de desesperação, escassez de objetivos de vida e problemas de cariz social, "questões que muitas das vezes uma pessoa passa ao lado mas que elas existem mesmo por baixo dos nossos olhos" (e. 1). Reiterando o interesse de ocupação de tempos livres, como meio de, elevar a autoestima, evitar a solidão e certas atitudes pouco dignificantes para a vida humana. Acrescentando, que a autarquia tem um papel decisivo no desenvolvimento destas iniciativas, "que nos obriga a nós autarquia termos uma postura, pode-se dizer cuidada para com essa mesma população" (e. 1) porque, ou os indivíduos não encontram o apoio necessário no seio familiar, devido à sua dinâmica, ou então estão 
confinados ao comodismo de "nada fazer", favorecendo o seu isolamento social. Interpelado a cerca da sua perspetiva sobre as atividades desenvolvidas, respondeu que esta transpusera as suas expectativas, "porque para além do número de pessoas que envolveu foi também muito importante o número de instituições que foram agregadas a este projeto, instituições que não fazem parte da vila que nos mostrou que realmente as nossas capacidades/recursos existentes na vila são exíguas a um projeto desta dimensão e com os objetivos a que nos propusemos" (e. 1), pois conseguiram envolver um grande número de pessoas e instituições criando sinergias e um aproveitamento de recursos essenciais ao objetivos propostos. Inquirido sobre o trabalho desenvolvido pela estagiária, frisou estar surpreendido pela positiva, sendo que esta se revelou uma pessoa presente, conhecedora dos objetivos propostos e com grande capacidade de ação, demonstrando também uma grande empatia com a população. Seguidamente foi interpelado pela evidencia de que ainda há muito por fazer, concluindo ser uma verdade absoluta, destacando que os projetos são temporários, deixando seu final um vazio. Por fim, quisemos saber se, na sua opinião, a temporalidade dos projetos, não deixa a população frustrada. Ao que respondeu concordar, completando que, as autarquias não conseguem acarretar os custos de um projeto e "torna-nos impotentes para conseguirmos atingir ou dar continuidade aos projetos e à nossa ação no campo social, porque isto é mesmo complicado" (e. 1), frisando que as instituições devem-se unir e munir de instrumentos/contributos financeiros estatais ou comunitários para conseguirem fazer frente/minimizar os custos referentes a estas iniciativas, contudo ressalva que ao nível dos recursos físicos e humanos, a questão é mais complicada, "nós aqui ao nível de recursos físicos não temos grandes soluções para que as pessoas possam... quer dizer, muitas das vezes até a questão do voluntariado é aproveitado e temos muitos exemplos disso" (e. 1).

Os testemunhos apresentados no seminario revelaram a unanimidade de todos em reconhecer a sua satisfação na participação nas atividades constituintes do projeto, como atestado por (t. AC) "foi maravilhoso, adorei participar" e (t. AP) "gostei muito, foi muito bom" acrescentando ainda, "é um projeto ao qual me orgulho de pertencer" (t. AP), estes testemunhos foram enriquecidos em poema, "hoje há mais alegria, mais vontade de viver, sentimos que há nova aurora, no horizonte a nascer" (t. AA). Na opinião expressa reconheceram que a sua participação foi "muito gratificante para nós, foi uma coisa benéfica” (t. AC), identificando ter sido "uma mais valia para toda a população sénior” (t. AP). Um elemento fazendo alusão às oficinas do projeto, refere "andamos sempre a estudar" (t. AA), um outro apontou gostar muito de aprender razão pela qual frequenta várias oficinas, este especificou ainda, o seu contentamento nas visitas efetuadas a outras instituições, "as visitas que fizemos, tudo isto nos alegra" (t. AP) e nos laços afetivos criados, corroborando a opinião representada em poema "temos ido a vários lados, sempre com muita alegria, visitamos infantários, e também centros de dia. E todos ficam contentes, com a nossa companhia" (t. AA). Aludiu ainda ter sido desafiado a sair da sua monotonía reconhecendo que mesmo com o avançar da idade, há muita coisa por fazer. Indicou ainda, com apreço, o número de pessoas que se foram juntando ao grupo, aumentando-o significativamente, "somos já um vasto grupo, mas a cada dia a aumentar" (t. AA). Um outroo participante esclareceu a sua conceção de envelhecimento ativo e os benefícios, explicando-os através de uma experiencia que teve, reforçando a relevância na existência de uma motivação extrínseca, a par da intrínseca "estou muito feliz por ter contribuído para a recuperação deste amigo" (t. AM). Em jeito de conclusão, todos concordaram com a pertinência de projetos desta natureza e da necessidade de apoio para que possam continuar, "era bom que um projeto como este tivesse apoio para continuar" (t. AP), nomeadamente, neste no qual estão inseridos, "esperemos que continue" (t. AC) insistindo de que "se terminar, não temos mesmo nada" (t. AC).

Partindo da opinião de todos os envolvidos, na avaliação do projeto, concluímos que este teve uma relevante contribuição para o desenvolvimento local e comunitário, o aumento da qualidade de vida, bem como para o alcance de novos conhecimentos/aprendizagens por parte dos implicados, uma vez que favoreceu o desenvolvimento de competências pessoais, sociais e culturais.

\section{Considerações}

Apelando a uma participação ativa dos agentes sociais realizaram-se atividades de cariz cultural, social, informativo/educativo, económico, desportivo, recreativo e/ou de voluntariado, procurando despertar nos indivíduos a relevância da ocupação dos tempos livres recorrendo a atividades de educação/formação e desenvolvimento pessoal, social e comunitário.

O projeto procurou dotar os participantes de ferramentas e competências emancipatórias e de empoderamento para uma melhor adequação a esta nova fase da vida. A intervenção teve resultados muito positivos dado que na avaliação final os participantes destacaram os benefícios do projeto, nomeadamente, ao nível de aquisição de novas competências (tecnologias de informação e comunicação; bordados; cantares; teatro) ao nível de novas aprendizagens (saúde; alimentação; ambiente; reciclagem) e ao nível do bem-estar físico e psicológico, do relacionamento interpessoal e da convivialidade. A par dos resultados positivos ao nível do desenvolvimento pessoal e melhoria da qualidade de vida, este projeto alcançou, ainda, reconhecida importância ao nível do desenvolvimento comunitário com resultados positivos na transformação de condições de vida e desenvolvimento local proporcionando, também, o desenvolvimento do intercâmbio intergeracional e interinstitucional. De salientar, ainda, o enfoque empreendedor assumido por várias oficinas/grupos, garantindo a sua sustentabilidade.

$\mathrm{Na}$ nossa opinião, os valores e princípios existentes no projeto estiveram na base do desenvolvimento pessoal e social, comprovado pelo sucesso conseguido, pela relação comunitária próxima criada, pela participação 
ativa dos envolvidos, além do reconhecimento conseguido.

\section{Referências}

Ander-Egg, E. (2000). Metodologia y práctica de la animación sociocultural Madrid: Editorial CCS.

Ander-Egg, E. (2003). Repensando la investigación acción-participativa. (4 ${ }^{\mathrm{a}} \mathrm{ed}$.). Buenos Aires: Grupo Editorial Lumen Hvmanitas.

Antunes, M. C. P. (2008). Educação, saúde e desenvolvimento. Coimbra: Edições Almedina, SA.

Antunes, M. C. P. (2015). Educar para um envelhecimento bem sucedido: reflexões e propostas. Teoría de la educación, 27 (2), 2015, 185-201. Disponível em: https://dialnet.unirioja.es/servlet/articulo? codigo $=534$ 0202. Consultado a 2 julho 2016.

Barros de Oliveira, J. H. (2005). Psicologia do envelhecimento e do idoso. ( $2^{\mathrm{a}}$ ed.). Porto: Legis Editora/Livpsic.

Bodgan, R. \& Biklen. S. (1994). Investigação qualitativa em educação, uma introdução à teoria e aos métodos. Porto: Porto Editora.

Cachioni, M \& Neri, A. L (2004). Educação e velhice bem-sucedida no contexto das universidades da terceira idade. In A. L Neri; M. S Yassuda (orgs.), Velhice bem-sucedida: aspectos afetivos e cognitivos (pp. 29-50). Campinas: Papirus.

Caride, J. A. (2004). Paradigmas teóricos na animação sociocultural. In J. Trilla (coord.), Animação sociocultural: teorias, programas e âmbitos (pp. 4563). Lisboa: Instituto Piaget.

Carrilho, M. J. \& Craveiro, M. L. (2014). A Situação Demográfica Recente em Portugal, Revista Estudos Demográficos, Lisboa: INE, I,P (54) 57-107. Disponível em: https://www.ine.pt/xportal/xmain? xpid=INE\&xpgid=i ne_publicacoes\&PUBLICACOESpub_boui $=2 \% 2010$ $786633 \&$ PUBLICACOESmodo $=2$. Consultado a 14 de janeiro 2016.

Castillo Arredondo, S. \& Cabrerizo Diago, J. (2003). Evaluación de programas de intervención socioeducativa: agentes y ámbitos. Madrid: Pearson Educación, SA.

Cieza García, J. A. \& González Sánchez, M. (1997). Desarollo humano, participación y dinamización sociocultutal. In J. García Carrasco (coord.), Educación de adultos (pp. 271-286). Barcelona: Editorial Ariel, S.A.

DGS (2012). Envelhecimento saudável. Ministério da saúde. Disponível em: https://www.dgs.pt/documentos-epublicacoes/envelhecimento-saudavel-pdf.aspx. Consultado a 2 de janeiro 2016.

Dias, J. R. (2009). Educação o caminho da nova humanidade: das coisas às pessoas e aos valores. Porto: Edições Papiro.

Eizirik, C.; Kapczinski, F. \& Bassols, A. M. (coords.) (2007). O ciclo da vida humana: uma perspectiva psicodinâmica. ( $2^{\mathrm{a}}$ ed.). Porto Alegre: Artmed.
Giroux, S. \& Trembay, G. (2011). Metodología de las ciências humanas: la investigación en acción. México: S.L. Fondo de Cultura Económica de España.

Hernandez Sampieri, R.; Baptista Lucio, P. e FernandezCollado, C. (2003). Metodología de la investigación. ( $3^{\mathrm{a}}$ ed.). México: McGraw-Hill.

Jacob, L. (2007a). Animação de Idosos. Porto: Âmbar. Oliveira, R. C., Oliveira, F. S. \& Scortegagna, P. A. (2010). Pedagogia Social: possibilidade de empoderamento para o idoso. In: III Congresso Internacional de Pedagogia Social, 3., São Paulo. Disponível em: http://www.proceedings.scielo.br/scielo.php?pid=MS C0000000092010000100022\&script=sci_arttext. Consultado a 5 de janeiro 2016.

OMS (2008). Guia global: cidade amiga do idoso. Genebra: OMS. Disponível em: http://www.who.int/ageing/GuiaAFCPortuguese.pdf. Consultado a 30 de novembro 2014.

OMS (2015). Relatório Mundial sobre Envelhecimento e Saúde. Genebra: OMS. Disponível em: http://sbgg.org.br/wp-content/uploads/2015/10/OMSENVELHECIMENTO-2015-port.pdf. Consultado a 20 de maio 2016.

ONU (2003). Plano de ação internacional contra o envelhecimento, 2002 / Organização das Nações Unidas. Brasília: Secretaria Especial dos Direitos Humanos, 2003. - (Série Institucional em Direitos Humanos; v. 1). Disponível em: http://www.observatorionacionaldoidoso.fiocruz.br/bi blioteca/_manual/5.pdf. Consultado a 20 de maio 2016.

Paúl, M. C. (1997). Lá para o fim da vida: idosos, família e meio ambiente. Coimbra: Livraria Almedina.

Witkin, B. R. \& Altschuld, J. W. (1995). Planning and conducting needs assessments: a practical guide. Thousand Oaks, CA: Sage. 